\title{
GEOINFORMATION MONITORING OF WATER USE IN LAKE BAIKAL BASIN
}

\begin{abstract}
The modern importance of optimizing the use of water resources in the Baikal natural territory $(\mathrm{BNT})$ is indicated. A universal methodology for a comprehensive assessment of the region's water management activities based on geo-information technology is proposed. The research stages are described, including the natural and economic zoning of the territory, the ranking by intensity of the aggregate anthropogenic load on water bodies and river basins, zoning of the territory to optimize the target use of water resources. The GIS of water use in the BNT on the basis of materials of federal statistical information is presented. According to the results of the geo-information analysis, 13 natural-economic areas with characteristic geo-ecological characteristics of water resources formation were identified and spatial regularities of location of water use objects in the investigated territory were revealed. As a result of zoning of the territory for the purposeful use of water resources, 5 zones were identified in the study area for the specific use of water objects, regulated by environmental restrictions on economic activities at the BNT, and also by the nature and intensity of the current and projected water use. A set of measures to optimize water use within the zones of targeted use of water resources is proposed. It is determined that the main water management activities in the study area are associated with the preservation of the ecological system of the lake Baikal and with the prevention of the negative impact of water use on its condition.
\end{abstract}

KEYWORDS: water use, water management objects, GIS, geoinformation assessment, zoning.

\section{INTRODUCTION}

The diversity of natural and climate conditions and the presence of territories with different regimes of ecological restrictions in nature development in the Baikal Natural Territory (BNT) have a considerable effect on the territorial and sectoral organization of water resources development in the Russian part of Baikal Basin, more than $72 \%$ of whose area is located in the territory of the Republic of Buryatia (RB). The optimization of water management activity requires determining regional specifics of water resources formation and the environmental consequences of their use, as well as reliable protection of local and background levels of anthropogenic load onto water objects and river basins. In this context, it was found necessary to divide the lake basin into zones of purpose-oriented management of water resources, ensuring the timely solution of the problems of territorial management and planning of environmentally safe water use. By now, a method for differentiating a territory by total anthropogenic load [Rybkina, 2011] and a procedure for evaluating water pollution index in the zone of influence of mining plants [Lozovik, 2014] have been developed. A procedure for assessing anthropogenic load onto a water body with respect to river flow in a studied section [Selezneva, 2007] is in wide use. A method has been proposed for identifying priority water-protection measures in a river basin based on target water quality characteristic [Belyaev, 2013]. To support managerial decisions in water management, a geoinformation algorithm was developed for the analysis and assessment

\footnotetext{
Baikal Institute of Nature Management, Siberian Branch, Russian Academy of Sciences, Sakhyanovoy str., 8 , 670047, Ulan-Ude, Russia, e-mail: abesh@mail.ru

2 Territorial Department of Water Resources for the Repubic of Buryatia, Yenisei Basin Water Administration, Borsoeva str., 3, 670000, Ulan-Ude, Russia, e-mail: dartsib@mail.ru
} 
of the geoenvironmental conditions of water use in river basins [Tsibudeeva, 2014] and databases are being formed to store and process data on water bodies [Petina, 2010]. Geoinformation methods are in wide use in different countries for the management and automation of water intake and treatment, sewerage, and water supply systems. In particular, the international Smart Water project implies the use of a GIS, incorporating models of water use and hydrosimulation, describing all events taking place in a water use system, along with their treatment rules and specified key efficiency characteristics [Kupriyanovskii, 2014].

\section{MATERIALS AND METHODS}

When determining the zones of purpose-oriented use of water resources, one faces the problem of integration of large bodies of spatial qualitative and quantitative characteristics of water management activity. The introduction of geoinformation technology will automate the use of water management data referring to different time intervals and enable reliable differentiation of a territory in terms of the specifics of the existing and anticipated water use. An important problem is the development of a universal methodological apparatus, which will enable the storage, accumulation, and analysis of vast volumes of water management information, including that on the environmental and economic aspects of water use, and will allow promptly answering requests and providing information.

This study generalizes many-year data of federal statistical reporting 2-TP (vodkhoz) and uses topographic and thematic maps, as well as remote-sensing data. The main hydrographic units in the study are water-management areas (WMAs), representing basin-scale river systems. The identification of WMAs is based on the need for effective management of water resources and meets the requirements of the approved hydrographic and water-management zoning of the Russian Federation. To optimize the regional water use, a method of geoinformation assessment of regional water use was developed, incorporating geoinformation procedures for formalization of statistical data, their assessment and analysis, the mapping of water management objects and processes, and the formulation of recommendations to improve the efficiency of territorial managerial decisions (Fig. 1).

According to the proposed method, the first stage includes studying the territory and forming an inventory of water use objects within the WMA and river basins by collecting data on the physiographic and socioeconomic conditions on the territory, and the sectoral directions of the economic use of water resources. The collection, treatment, and analysis of geodata, characterizing the objects and processes of regional water use, are carried out in ArcGIS geoinformation environment. Therefore, the result of the first stage is the creation of a GIS of the area under study and a database of water management objects and processes. The functional task of such system is the continuous spatial and qualitative-quantitative information-based assessment of water use in the territory interrelated with the environmental assessment of the effects of water-management activities. The final product of the system is a set of universal cartographic models and typical geoinformation requests regarding the development of objects and territories of water use, which form under the effect of users' requirements.

Data on groups of single-type water-management objects are logically organized into digital thematic layers. The qualitative-quantitative data on objects are combined into an attribute table in the form of a set of numbers or symbols and referred to coordinates through a unique identifier of the object. For different-time data, additional time identifiers are introduced and the objects are organized into thematic layers for different time moments. A relational model of geodata presentation is used in geoinformation technology to form an attributive model of the storage of data on water management object. In addition to water management data, digital thematic layers (landscapes, soils, land use, etc.) are also used in GIS. The geoinformation mapping 
and combining all layers results in the formation of a cartographic cover for assessing water use in river basins, which contains attributes of all combined layers. In this case, for the layer "Water Management Areas," a database on water use is formed, containing different-time characteristics of water intake and discharge, limits and quotas of water resources withdrawal from water objects, and the characteristics of water quality and pollution.

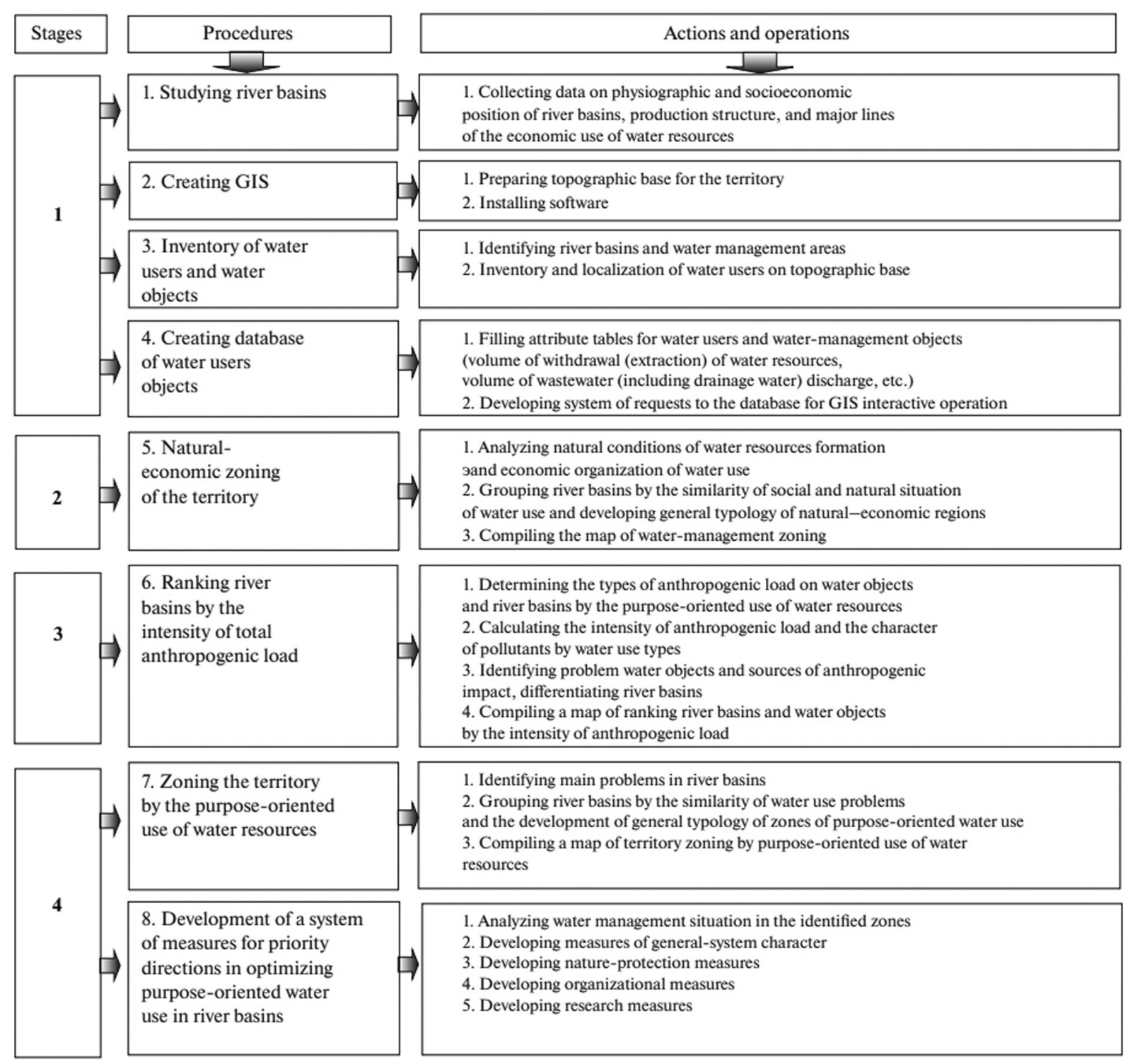

Fig. 1. Method of geoinformation monitoring of water use

The interactive work with the database is implemented through information requests. For example, in the case of a request "to rank river basins by the dynamics of water withdrawal in 2006-2014," the first step of request processing will be the choice of simulation objects (river basins). Next, water withdrawal in the basin is recorded (water withdrawal) and automated assessment of the process is implemented (water withdrawal dynamics). The result of these operations is that GIS formulates an answer in cartographic, graphic, and tabular form. The cartographic model reflects the spatial development of the phenomenon and territory with a positive (water intake has increased) and negative (water intake has decreased) dynamics; the graphic model gives a quantitative estimate of the process as a whole for each WMA; and the tabular model is a relational table, containing metric parameters of water use characteristics. 
At the second stage, the physiographic features of river basins, WMA, and water use objects are assessed. The mapping gives the boundaries of WMAs and administrative regions in whose territory they are located and refers the populated localities and water objects to administrative regions and river basins. The next step is the analysis of the natural conditions under which water resources are formed and the socioeconomic organization of water use. This includes the assessment of orographic, climatic, hydrological, and hydrochemical conditions, water regime types of rivers, and the existing types of water use. The result of the second stage of the procedure is the naturaleconomic zoning of the territory, i.e., the division of river basins into zones by the geoecological conditions of water use, considering the wide natural diversity of river basins and subbasins, the specifics and intensity of their economic development, as well as the current ecological restrictions on water use in BNT. For example, two regions were chosen in the Selenga basin:

(1) Selenga medium-mountain-low-mountain, taiga-subtaiga-steppe region of multipurpose use;

(2) Ust'-Selenga low-mountain-lowland, subtaiga and delta-medow-bog region of fishery and agricultural use.

At the third stage, thematic layers are introduced in GIS, corresponding to the territorial distribution of industrial and agricultural enterprises, concentration of population in each administrative region and river basin, and appropriate statistical data. Next the load per basin unit area is calculated: industrial, by the volumes of industrial production; demographic, by population size; agricultural, by the cattle population and arable land areas. The obtained results form the basis for calculating the total anthropogenic load onto the drainage area. Wastewater load onto water bodies is estimated as the ratio of the total wastewater discharge volume to the mean long-term river water discharge at a given gage [6]. To assess the environmental conditions of water objects, water consumption and disposal are mapped with identification of surface water pollution sources. The result of estimation is the ranking of the territory by the intensity of total anthropogenic load.

The geoinformation analysis of the layers of natural-economic zoning and the ranks of river basins by the total anthropogenic load are used at the fourth stage to identify problem territories and water objects, to reveal the causes of the problems, and to assess the dynamic of anthropogenic impact. Next, the territory is differentiated into individual zones of purpose-oriented use of water resources with similar natural and socioeconomic conditions, single-type water use regime, the type of water resources use, similar levels of total anthropogenic load. The final step in the procedure is the development, for each zone, of a system of measures for improving regional water use in river basins and recommendations for creating optimal conditions for rational and environmentally safe water use.

\section{RESULTS}

The natural-economic zoning of RB territory identifies 13 regions with characteristic geoecological conditions of water resources formation, which differ in the territorial-sectoral structure of water use and the specifics of the economic development of the territory, as well as the actual environmental restrictions in the use of water resources in BNT. Spatial regularities were identified in the distribution of water use objects in RB territory:

agricultural objects are mostly localized in the steppe and forest-steppe southern and southeastern RB regions with favorable agroclimatic conditions;

recreation objects are concentrated along Lake Baikal coast in accordance with the specific environmental status of the BNT;

industrial and municipal objects are distributed irregularly with a center in the middle reaches of the Selenga Basin.

The assessment and ranking of river basins and water objects by the size of anthropogenic load revealed environmental problems in the region and their spatial localization and identified the 
exact location of pollution sources and their effect on water management situation. The intensity of the total anthropogenic load on river basins is estimated by the parameters of areal and point impact, and $\mathrm{RB}$ water objects were ranked by the load of wastewater and pollutants on them. The ranking of river basins by the total anthropogenic load showed that the demographic, industrial, and agricultural impact is largest in the Selenga R. Basin in its middle reach; the load is very small in the peripheral river basins with severe climate conditions, poor transport infrastructure, and weakly developed economy.

The results of RB zoning by the purpose-oriented use of water resources were used to identify five zones in the examined territory by the formation conditions of water resources and the specifics of the use of water objects, subject to environmental limitations of economic activity on BNT and by the character and intensity of the existing and anticipated water use. The scheme of territorial zoning is the geoecological basis of the examined part of Baikal Basin for the development of targeted system of federal and municipal measures for ensuring the sustainable and safe water use in river basins, for reducing all types of anthropogenic load and maintaining the quality of natural waters (Fig. 2).

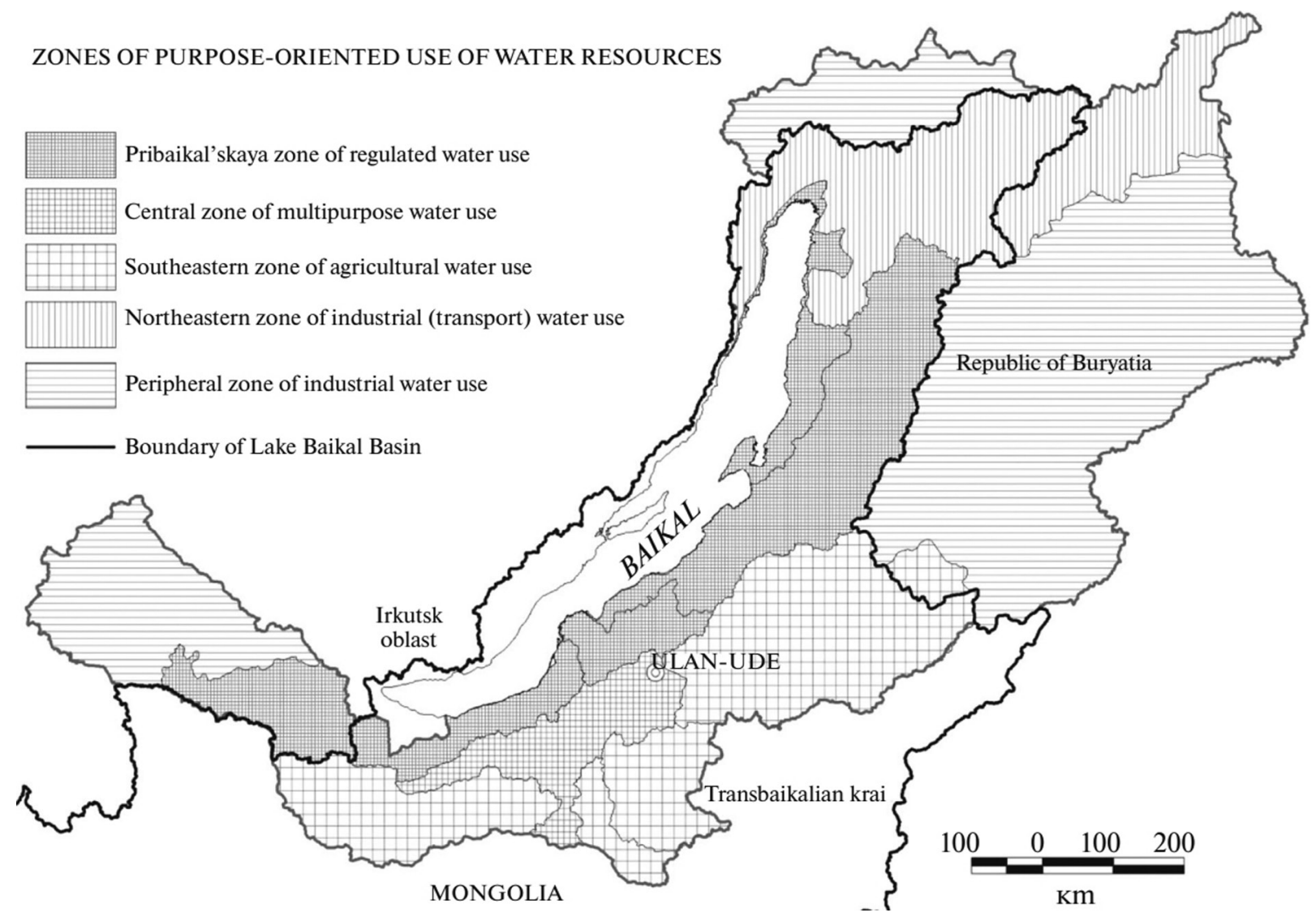

Fig. 2. Zoning the territory of the Republic of Buryatia by the purpose-oriented use of water resources

To optimize the water use in each zone, a system of scientific and engineering recommendations was developed, aimed to ensure water supply to the economy and population by water of appropriate quality, considering the regional features of water resources formation and the perspectives of socioeconomic development of the territory. The system of measures is underlain by the provisions of RF Water Code, Water Strategy, FL "On the Protection of Lake Baikal," federal and regional purpose-oriented programmes, orders and decrees of RF Government.

The Baikal Zone of regulated water use includes the basins of the Irkut and Selenga rivers in their lower reaches, as well as the basins of Lake Baikal tributaries in its northern, middle, and southern 
parts (according to RF hydrographic zoning), which fully or partially enter the Central Ecological Zone of BNT. Irkut R. Basin is included in this zone because of the Tunkinskii National Park, located in its area and confined to the depression with the same name, which is a part of the Baikal Rift Fault.

The major water-management measures in the zone are aimed to preserve the ecological system of Lake Baikal and to prevent the adverse effect of water use on its state. The measures include the following: technical upgrading and reconstruction of the existing water disposal systems based on up-to-date wastewater treatment technologies, the assessment of the actual recreation load on water objects and their watersheds, monitoring the coastal and water areas for prompt identification of the signs of eutrophication of water streams and bodies, the construction of up-to-date tourist resorts with developed engineering infrastructure, minimization of the adverse effect on water resources of unorganized tourism.

The Central Zone of multipurpose water use covers the Selenga R. Basin in its middle reach. The intense water use here contributes to largest pollution of natural water in the basin; hence, water protection and water-saving measures are to be taken: modernization of wastewater treatment facilities with the use of upto-date technologies and equipment for treatment; reduction of ineffective consumption by introducing modern water gages and new sanitary equipment, reduction of losses in engineering networks; accounting for diffuse runoff from economically developed territories; assessment of the effect of forest cutting on the hydrological regime of rivers and the formation of surface and subsurface runoff. In addition, integrated studies are to be carried out to assess the effect of the Gusinoozerskaya SDPP and polluted wastewaters from Gusinoozersk T. on the hydrological and hydrochemical regimes of Lake Gusinoe, as well as the development of simulation models of territorial runoff distribution of water objects in the Selenga Basin.

In the Southeastern Zone of agricultural water use, water resources are mostly used in agriculture, while the volumes of household water use and seasonal water withdrawal for irrigation are insignificant. When planning the intensification of agricultural production, attention should be paid to the possible future excessive water withdrawal from rivers, especially in dry periods. Programs are to be developed and implemented for the recovery of water objects (especially, small and very small streams) and anthropogenically disturbed watersheds; the discharge volumes of polluted wastewater are to be reduced stage by stage; effective systems of centralized water supply and disposal are to be developed; the ecological safety of engineering means and technologies in agriculture should be improved; the measures to be implemented are to include monitoring river runoff changes in steppe zone under the effect of agricultural activity and analysis and reduction of diffuse runoff from economically developed territories; the application of chemical fertilizers and other hazardous substances is to be strictly controlled, and their environmentally safe storage is to be ensured; the effect of forest cutting on the hydrological regime of rivers and the formation of surface and subsurface runoff is to be evaluated; simulation models are to be developed for pollutant propagation from point and diffuse sources; irrigation systems are to be modified with the use of up-to-date technologies of water intake for irrigation of agricultural lands; the effect of coal-mining industry on water objects and the drainage areas of the Tungnui, Sukhara, and Khilok is to be studied.

The Northeastern Zone of industrial (transport) water use includes river basins of the northern Baikal Basin and the reach of the Vitim R. from Spitsino Settl. to Bodaibo T. The Baikal-Amur Mainline passes here. In RB development program, the SeveroBaikal'skii raion is regarded as a zone of development of tourism of natural-ecological, medicinal, and sport and health-improving directions. The major water protection measures are to include the increase in the share of legitimate water use, the prompt reconstruction of treatment facilities, in rationalization of water resources use by equipping water intake stations by monitoring instruments.

The Peripheral zone of industrial water use includes the basins of Angara left tributaries and the upper reaches of the Vitim R., where water is used by gold-mining teams and gold mines. 
The problems of water use are mostly related with the adverse ecological effects of mining plants operation (river pollution by heavy metals, channel deformations, etc.). In this case, comprehensive analysis of the effect of placer and hardrock gold mining on the ecosystems of river basins is required along with the construction of water-intake wells and the development of effective systems of centralized water supply and disposal.

\section{CONCLUSIONS}

The developed universal method for integrated studies of regional water use ensures reliable estimation and analysis of the main aspects of water-management activity. It can be applied to any territories as the geoinformation support of territorial water management. The application of the method revealed the physiographic and socioeconomic regularities in the organization of water use in the Russian part of Lake Baikal Basin. For the first time, river basins were ranked by the intensity of total anthropogenic load on them. The zoning of the territory by the purpose-oriented use of water resources enabled the development of a system of measures to ensure the sustainable and safe water use in river basins and the reduction of all kinds of anthropogenic load on water objects. The developed GIS of water use is a program-controlled complex of continuously recording and assessing the processes of formation and use of water resources; it meets the international requirements to such products, is open for supplementing it with qualitative and quantitative data. The introduction of the GIS in the functioning of governmental agencies for management and planning of the neighboring states (Mongolia) will contribute to more efficient intergovernmental nature-protection and socioeconomic interaction in the sphere of transboundary water object management.

\section{REFERENCES}

1. Belyaev S.D., Mikhailova T.I., Odintseva G.Ya., Chaikina T.I. The choice of priorities in water protection activity based on water quality targets: case study of the Oka Basin, Vod. Khoz. Rossii: Probl., Tekhnol., Upravl. 2013. No 2. P. 6-25 (in Russian).

2. Kupriyanovskii V.P., Tishchenko P.A., Raevskii M.A., Shilov I.V., Shchichko A.S. Smart Water: Integrated Water Resources Management Based on Smart Technologies from Esri and IBM, ArcRev. 2014. V. 68, No 1. Web resource http://www.dataplus.ru/news/arcreview/detail.php? ID $=17017 \&$ SECTION_ID $=1048$ (in Russian).

3. Lozovik P.A., Kulakova N.E. Methodological approaches to pollution assessment in water bodies within the operation zone of mining plants, Water Resources. 2014. V. 41, No 4. P. 464-472 (in Russian).

4. Petina M.A. The use of geoinformation technologies in decision support systems in water resources management: case study of Belgorod oblast, Nauch. Vedom., Ser. Estestv. Nauiki, 2010. V. 92, No 21. Iss. 13. P. 150-156 (in Russian).

5. Rybkina I.D, Stoyashcheva N.V., Kurepina N.Yu. Method for zoning river basin territory by total anthropogenic load: case study of Ob-Irtysh Basin, Vod. Khoz. Rossii: Probl., Tekhnol., Upravl., 2011. No 4. P. 42-52 (in Russian).

6. Selezneva A.V. From Monitoring to Standardization of Anthropogenic Load on Water Objects. Samara: Sam. Nauch. Ts., Ross. Akad. Nauk, 2007 (in Russian).

7. Tsibudeeva D.Ts. Geoecological conditions of water use in river basins of the Republic of Buryatia. PhD dissertation. Barnaul, 2014. 187 p. (in Russian). 